\begin{tabular}{|c|c|c|}
\hline \multirow{3}{*}{$\begin{array}{r}\text { Case Reports in } \\
\text { Gastroenterology }\end{array}$} & \multirow{2}{*}{\multicolumn{2}{|c|}{ Case Rep Gastroenterol 2018;12:56-62 }} \\
\hline & & \\
\hline & $\begin{array}{l}\text { DOI: 10.1159/000486389 } \\
\text { Published online: February 1, } 2018\end{array}$ & $\begin{array}{l}\text { (c) } 2018 \text { The Author(s) } \\
\text { Published by S. Karger AG, Basel } \\
\text { www.karger.com/crg }\end{array}$ \\
\hline & $\begin{array}{l}\text { This article is licensed under the } \\
\text { International License (CC BY-NC) } \\
\text { Usage and distribution for commerc }\end{array}$ & $\begin{array}{l}\text { nons Attribution-NonCommercial } 4.0 \\
\text { ger.com/Services/OpenAccessLicense). } \\
\text { uires written permission. }\end{array}$ \\
\hline
\end{tabular}

\title{
Adult Presentation of Noncirrhotic Portal Hypertension and Ascites following Treatment for Wilms" Tumor in Childhood
}

\author{
Linda Kievit $^{\mathrm{a}} \quad$ Pia Kræmer ${ }^{\mathrm{b}} \quad$ Stephen Hamilton-Dutoit ${ }^{\mathrm{c}}$ \\ Henning Grønbæk ${ }^{a}$ \\ ${ }^{a}$ Department of Hepatology and Gastroenterology, Aarhus University Hospital, \\ Aarhus, Denmark; ${ }^{b}$ Department of Endocrinology, Aarhus University Hospital, \\ Aarhus, Denmark; ${ }^{C}$ Institute of Pathology, Aarhus University Hospital, Aarhus, Denmark
}

\section{Keywords}

Ascites · Noncirrhotic portal hypertension · Portal hypertension · Wilms' tumor

\begin{abstract}
A 37-year-old male, who at the age of 8 years had been treated for right-sided Wilms' tumor with nephrectomy, radiotherapy, and chemotherapy, presented with noncirrhotic portal hypertension (NCPH), grade 2 esophageal varices, and ascites. A CT scan demonstrated hypoplasia of liver segments 2 and 3. A liver biopsy showed portal tract fibrosis without cirrhosis, with histological features of NCPH. Liver vein catheterization showed a normal portal pressure gradient of $5 \mathrm{~mm} \mathrm{Hg}$ while spleen to hepatic vein pressure was $29 \mathrm{~mm} \mathrm{Hg}$. NCPH after therapy for Wilms' tumor is described in children within the first few years after treatment. This is the first case report in which the patient first presented symptoms as an adult, many years after cancer treatment.

(C) 2018 The Author(s)

Published by S. Karger AG, Basel
\end{abstract}




\section{Introduction}

Wilms' tumor (WT) or nephroblastoma is a rare primary renal tumor, affecting approximately 8 in a million children. It is the most common childhood tumor of the kidney and is associated with a variety of syndromes [1]. Prognosis depends mostly on the TNM stage and histological characteristics. The overall survival has improved over the years, but at the same time the degree of late complications and side effects has increased [1,2].

For more than 30 years, standard therapy for WT has been a combination of surgery, chemotherapy (vincristine, actinomycin D, and doxorubicin), and radiation therapy. However, in light of WT patients' excellent survival rates, and because of the high risk of treatmentrelated late side effects, treatment regimens have been modified substantially over recent years. Thus, fewer patients now receive radiotherapy compared with 30 years ago, without any significant change in prognosis [2].

The 5-year survival rate for WT is now approximately $90 \%$, with $65 \%$ of patients surviving beyond 30 years. Premature mortality in WT patients is primarily caused by secondary cancers and cardiac disease, and by a variety of other complications that have been described as a result of therapy. One of the more common of these complications is the development of noncirrhotic portal hypertension (NCPH). NCPH has been reported previously in children, within 6 years of tumor diagnosis. However, we here describe a patient who developed NCPH with associated esophageal varices and ascites 29 years after treatment for a right-sided WT in childhood. We present the case and a review of the literature.

\section{Case Report}

A 37-year-old male was seen in the outpatient clinic because of weight loss, fatigue, and abdominal discomfort. Current height was $175 \mathrm{~cm}$, weight $67 \mathrm{~kg}$, with an unintended weight loss of $6 \mathrm{~kg}$ over the last few months. There had been symptoms of fatigue, which the patient attributed to increased workload. The abdominal discomfort included distention without pain or nausea. There were normal and unchanged stools and no icterus.

The patient had no other symptoms at presentation and showed a good performance status. At age 8, he had been diagnosed with right-sided WT with metastases to lymph nodes and lungs, and with thrombosis of the inferior vena cava and right renal vein. He was treated with intended curative right-sided nephrectomy and thrombosis evacuation, in combination with adjuvant radiation and chemotherapy. He received chemotherapy pre- and postoperatively with dactinomycin, actinomycin D, and vincristine, and 20 cycles with 30 Gy of radiation treatment to the right side of the abdomen for lymph node metastases. There was a cover over a large portion of the right lobe of the liver.

The patient had mildly elevated liver enzymes during the pre- and postoperative chemotherapy, with a maximum ASAT at $224 \mathrm{U} / \mathrm{L}(10-40)$, an elevated alkaline phosphatase level between 350 and $650 \mathrm{U} / \mathrm{L}(80-250)$, with persistent normal $\gamma$-glutamyltransferase.

The liver enzymes normalized after the end of treatment. There was no evidence of hepatomegaly, jaundice, ascites or liver pain during the 10 years of follow-up after radiation and chemotherapy. Follow-up included periodically clinical evaluation, blood tests, wholebody CT scan, ultrasound of the abdomen, and a plain thoracic X-ray. Blood tests were normal apart from a moderate thrombocytopenia at 90-125 × 109/L (150-450). Radiographically, there were venous collaterals at the level of the previous inferior vena cava thrombosis. In addition, ultrasound showed slowly progressive splenomegaly to $16 \mathrm{~cm}$ developing 
over the years, which was not further investigated. Five years after treatment, an abnormal ultrasound pattern was observed in the liver parenchyma without signs of cirrhosis and normal flow in the portal and liver veins; no further action was taken. At the age of 18, after 10 years of follow-up, the patient was discharged in a clinically stable condition. Hereafter, the patient had had no contact with the health care system until the current admission.

On admission, aged 37, the patient's physical presentation was normal, apart from the findings of cutaneous abdominal varices and an enlarged spleen. Laboratory examinations showed elevated ALAT at $115 \mathrm{U} / \mathrm{L}$ (10-70), alkaline phosphatase at $199 \mathrm{U} / \mathrm{L}$ (35-105), low albumin at $35 \mathrm{~g} / \mathrm{L}(36-48)$, normal bilirubin at $22 \mu \mathrm{mol} / \mathrm{L}(5-25)$, and thrombocytopenia at $75 \times 10^{9} / \mathrm{L}$ (145-350). Other results, including a full blood count and screening for metabolic, viral, and autoimmune liver disease, were all normal. A CT scan of the thorax/abdomen showed no sign of malignancy, but hypoplasia of liver segments 2 and 3 was seen, a reduced perfusion in the liver segments 6 and 8 as well as splenomegaly at $18 \mathrm{~cm}$. In addition, several enlarged lymph nodes $(1-3 \mathrm{~cm})$ were observed in the retroperitoneum and around the celiac trunk and radiation sequelae in the right colon (Fig. 1). A lymph node biopsy showed reactive changes without evidence of malignancy and bone marrow biopsy was normal. A colonoscopy revealed minor inflammation, histologically compatible with radiation sequelae.

Two months after initial presentation, the patient developed ascites and new imaging with CT and ultrasound showed otherwise unchanged conditions. A gastroscopy revealed grade 2 esophageal varices.

A needle biopsy of the liver was performed. This revealed an enlargement of most portal tracts, with varying mild to moderate fibrosis. There was some degree of periportal fibrosis, but only occasional short septa with no evidence of bridging fibrosis or of cirrhosis. Several of the fibrotic portal tracts showed evidence of obliterative portal venopathy, normal portal veins being either lost (with evidence of replacement by many smaller vascular structures), or showing sclerosis with fibrous thickening of the portal vein wall (Fig. 2a). In other portal areas, portal veins were dilated with herniation into the surrounding liver parenchyma (socalled periportal shunt vessels; Fig. 2b).

A combined liver vein and spleen pulp pressure measurement was performed as previously described [3] and showed a normal pressure gradient across the liver ( $5 \mathrm{~mm} \mathrm{Hg}$ ), but a high gradient from the spleen to the free hepatic vein $(29 \mathrm{~mm} \mathrm{Hg})$. This confirmed the expected presinusoidal hepatic origin of the patient's NCPH.

The patient was treated with loop diuretic medicine and an aldosterone antagonist for ascites and propranolol was administered to reduce the portal pressure gradient. As a result, the patient became asymptomatic without ascites and is able to work full time.

\section{Discussion}

We believe this to be the first reported case of NCPH to develop in a WT patient as a side effect of radiation and chemotherapy in childhood, in which the primary presentation was in adulthood.

There are a number of reports of the development of NCPH in children after treatment for WT [4-6]. However, these all developed within the first few years after treatment. Patients are typically presenting with variceal bleeding within 2-5 years following nephrectomy. In these cases, the pathological changes reported in liver biopsies are consistent with either acute or more chronic radiation-induced liver disease (RILD) [4-6]. A case control study on WT-treated patients showed that all cases of NCPH occurred within 6 years of WT 
diagnosis and treatment [7]. The cumulative risk for development of NCPH at 6 years was $0.7 \%$ for patients with right-sided WT and $0.1 \%$ for patients with left-sided WT. This study also showed that development of NCPH was strongly associated with radiotherapy. A minimum dose of $15 \mathrm{~Gy}$ to the liver was associated with development of $\mathrm{NCPH}$, with increasing incidence according to radiation dose to the liver [7].

Hepatic toxicity is a well-known complication of cancer treatment in general, and both radiotherapy and chemotherapy may be involved in hepatotoxicity in WT patients. RILD after conventional fractionated radiotherapy was described several decades ago, and symptoms typically appear 4-8 weeks after completion of treatment $[8,9]$. A number of pathophysiological changes are described as a result of liver irradiation. The early phase is characterized by hyperemia and reticulin and collagen fiber formation $[9,10]$. These pathological changes are often transient, but development of chronic radiation hepatitis is described with obliteration of the centrilobular veins, parenchymal cell loss, and collapse and distortion of the lobular architecture [11].

The pathophysiological changes of RILD are similar to those seen in veno-occlusive disease (VOD). VOD is a well-known complication of bone marrow transplantation, but may also be seen after treatment with various drugs, e.g., actinomycin D [12]. Several case reports of acute clinical VOD after chemotherapy for WT are reported in the literature [13-15]. The condition is interpreted as an unusual hepatotoxic reaction and is seen in up to $8 \%$ of the treated children $[16,17]$. The diagnosis is primarily based on clinical features of jaundice, hepatomegaly, upper right quadrant pain and ascites. Histopathological confirmation of VOD has been reported in only very few cases $[16,18]$. The condition is typically transient, but may last from a few days until a couple of months. Risk factors for development of VOD after chemotherapy are young age and concomitant radiotherapy [16].

Both RILD and VOD are most often seen transiently in the acute phase after radiation and chemotherapy. Our patient did not have clinical signs of RILD or VOD at the time of treatment or in the first years of follow-up. However, the patient had a marginally enlarged spleen at diagnosis, which slowly progressed during follow-up and was interpreted as a consequence of the previous vena cave inferior thrombosis. Persistent splenomegaly has been described in other patients after right-sided irradiation for WT and may suggest long-term alterations in the portal circulation and development of NCPH [19].

Our patient was first diagnosed with NCPH 29 years after diagnosis and treatment of right-sided childhood WT. This is a markedly later presentation than in previous reports. In children with WT, the cumulative risk for development of NCPH is substantially greater after right-sighted, compared with left-sided tumors [19]. Given that the original WT in our patient was right-sided, this provides circumstantial evidence for WT treatment being the likely cause of NCPH in our patient. In general, the histological diagnosis of NCPH on liver needle biopsy may be challenging. However, our patient's liver biopsy showed several morphological features that have been well-described in cases of NCPH of varying etiology. In particular, the presence of portal tract fibrosis, obliterative portal venopathy, portal vein sclerosis, and periportal shunt vessel formation, together with the absence of bridging fibrosis or other evidence of cirrhosis, attest to the diagnosis. Furthermore, we confirmed that the patient had true NCPH by combined liver vein catheterization and spleen pressure measurement. Although our patient had no clear symptoms of NCPH until his presentation, it is possible that he may have had slowly progressive liver disease following his cancer treatment, with a long-lasting latent phase with sudden deterioration in adulthood.

Increasing numbers of WT patients are long-time survivors after treatment, suggesting that more cases may be expected in the future to present with NCPH and its complications. 
Early recognition and correct treatment of these late side effects and their complications are important for the quality of life and continued survival of these long-term cancer survivors.

\section{Statement of Ethics}

Patient consent was obtained. No ethics review was required.

\section{Disclosure Statement}

All authors declare that there is no conflict of interest.

\section{References}

1 DeVita V, Lawrence T, Rosenberg S: DeVita, Hellman, and Rosenberg's Cancer: Principles and Practice of Oncology. Philadelphia, Wolters Kluwer Health/Lippincott Williams \& Wilkins, 2011, chapt 50.2, pp 2050-2057.

2 Wong KF, Reulen RC, Winter DL, Guha J, Fidler MM, Kelly J, et al: Risk of adverse health and social outcomes up to 50 years after Wilms tumor: the British Childhood Cancer Survivor Study. J Clin Oncol 2016;34:1772-1779.

3 Keiding S, Solvig J, Gronbaek H, Vilstrup H: Combined liver vein and spleen pulp pressure measurements in patients with portal or splenic vein thrombosis. Scand J Gastroenterol 2004;39: 594-599.

4 Thomas PR, Griffith KD, Fineberg BB, Perez CA, Land VJ: Late effects of treatment for Wilms' tumor. Int J Radiat Oncol Biol Phys 1983;9:651-657.

5 Roback SA, Nesbit ME Jr, Sharp HL, D’Angio GJ, Leonard AS: Portal hypertension following surgery, X-radiation, and actinomycin D therapy of nephroblastoma. J Pediatr 1971;78:1031-1034.

6 Barnard JA, Marshall GS, Neblett WW, Gray G, Ghishan FK: Noncirrhotic portal fibrosis after Wilms' tumor therapy. Gastroenterology 1986;90:1054-1056.

7 Warwick AB, Kalapurakal JA, Ou SS, Green DM, Norkool PA, Peterson SM, et al: Portal hypertension in children with Wilms' tumor: a report from the National Wilms' Tumor Study Group. Int J Radiat Oncol Biol Phys 2010;77:210-216.

8 Ingold JA, Reed GB, Kaplan HS, Bagshaw MA: Radiation hepatitis. Am J Roentgenol Radium Ther Nucl Med 1965;93:200-208.

9 Reed GB Jr, Cox AJ Jr: The human liver after radiation injury. A form of veno-occlusive disease. Am J Pathol 1966;48:597-611.

10 Fajardo LF, Colby TV: Pathogenesis of veno-occlusive liver disease after radiation. Arch Pathol Lab Med 1980;104:584-588.

11 Haschek W, Rousseaux C, Wallig M: Response to injury induced by ionizing radiation; in Haschek W Rousseaux C, Wallig M (eds): Haschek and Rousseaux's Handbook of Toxicologic Pathology, ed 3. Philadelphia, Elsevier Inc, 2013, chapt 44, pp 1452-1453.

12 Valla DC, Cazals-Hatem D: Sinusoidal obstruction syndrome. Clin Res Hepatol Gastroenterol 2016;40:378-385.

13 Tornesello A, Piciacchia D, Mastrangelo S, Lasorella A, Mastrangelo R: Veno-occlusive disease of the liver in right-sided Wilms' tumours. Eur J Cancer 1998;34:1220-1223.

14 Zoubek A, Wiesbauer P, Pracher E, Martins da Cunha AC, Emminger W, Grois N, et al: Veno-occlusive disease of the liver as a treatment complication in children with Wilm's tumor. Padiatr Padol 1992;27:47-50.

15 Hazar V, Kutluk T, Akyuz C, Varan A, Yaris N, Buyukpamukcu M: Veno-occlusive disease-like hepatotoxicity in two children receiving chemotherapy for Wilms' tumor and clear cell sarcoma of kidney. Pediatr Hematol Oncol 1998;15:85-89.

16 Bisogno G, de Kraker J, Weirich A, Masiero L, Ludwig R, Tournade MF, et al: Veno-occlusive disease of the liver in children treated for Wilms tumor. Med Pediatr Oncol 1997;29:245-251.

17 Czauderna P, Katski K, Kowalczyk J, Kurylak A, Lopatka B, Skotnicka-Klonowicz G, et al: Venoocclusive liver disease (VOD) as a complication of Wilms' tumour management in the series of consecutive 206 patients. Eur J Pediatr Surg 2000;10:300-303. 
Kievit et al.: Adult Presentation of Noncirrhotic Portal Hypertension and Ascites following Treatment for Wilms' Tumor in Childhood

18 Jagt CT, Zuckermann M, Ten Kate F, Taminiau JA, Dijkgraaf MG, Heij H, et al: Veno-occlusive disease as a complication of preoperative chemotherapy for Wilms tumor: a clinico-pathological analysis. Pediatr Blood Cancer 2009;53:1211-1215.

19 Samuels LD: Paradoxical splenic enlargement following radiation therapy. Radiology 1972;104: 389-391.

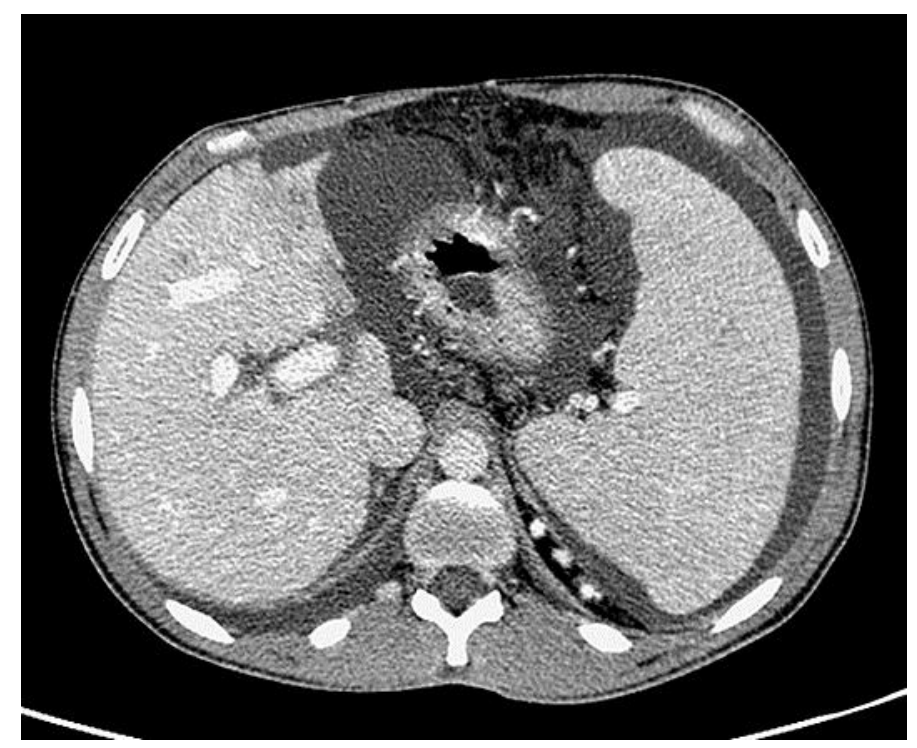

Fig. 1. CT scan of the abdomen showing ascites, splenomegaly, and hypoplasia of the liver segments 2 and 3. 


\section{Case Reports in \\ Gastroenterology}

\begin{tabular}{l|l}
\hline Case Rep Gastroenterol 2018;12:56-62 \\
\hline DOI: 10.1159/000486389 & $\begin{array}{l}\text { @ 2018 The Author(s). Published by S. Karger AG, Basel } \\
\text { www.karger.com/crg }\end{array}$ \\
\hline
\end{tabular}

Kievit et al.: Adult Presentation of Noncirrhotic Portal Hypertension and Ascites following Treatment for Wilms' Tumor in Childhood

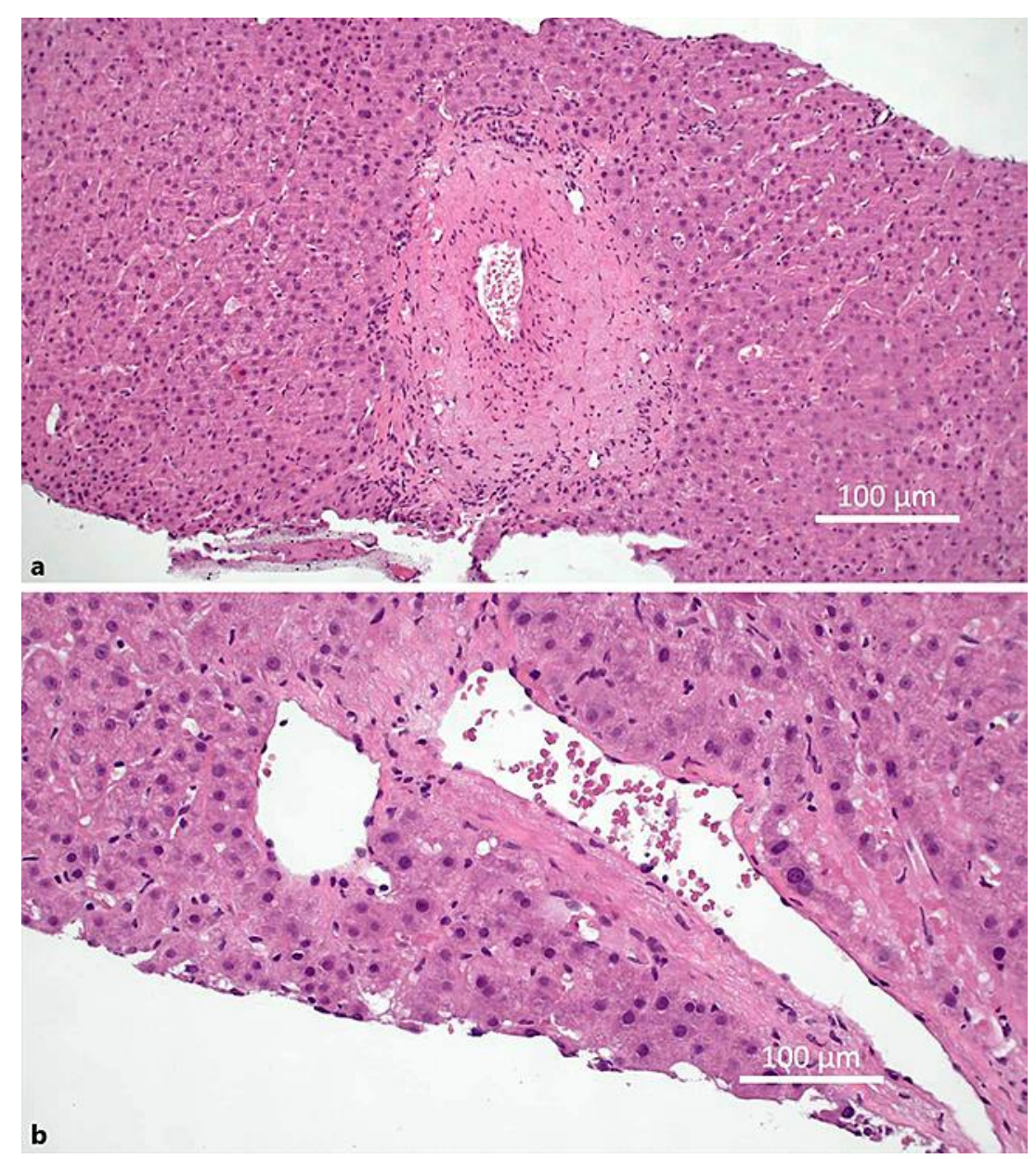

Fig. 2. a An expanded portal tract showing fibrosis without septa. There is no evidence of cirrhosis. Centrally, a large portal vein shows sclerosis with fibrous thickening of the vessel wall (H\&E). b A fibrotic portal tract containing an abnormally dilated portal vein. To the left, there is associated herniation of the vein into the adjacent hepatic lobule (a so-called periportal shunt vessel) (H\&E). 